\title{
Both common and specialty mushrooms inhibit adhesion molecule expression and in vitro binding of monocytes to human aortic endothelial cells in a pro-inflammatory environment
}

\author{
Keith R Martin
}

\begin{abstract}
Background: Cardiovascular disease (CVD) is a leading cause of mortality in the United States as well as globally. Epidemiological studies show that regular fruit and vegetable consumption reduces CVD risk, in part, due to antioxidant activity and immunomodulation since oxidative stress and inflammation are features of atherogenesis. Accumulating evidence also shows that dietary fungi, viz., mushrooms, can protect against chronic disease by altering inflammatory environments such as those associated with CVD although most research has focused on specialty mushrooms. In this study, we tested the ability of both common and specialty mushrooms to inhibit cellular processes associated with CVD.
\end{abstract}

Methods: Human aortic endothelial cells (HAEC) were incubated overnight with control media with dimethylsulfoxide (DMSO) vehicle ( $1 \% \mathrm{v} / \mathrm{v})$ or containing DMSO extracts of whole dehydrated mushrooms $(0.1 \mathrm{mg} /$ $\mathrm{mL}$ ), which included Agaricus bisporus (white button and crimini), Lentinula edodes (shiitake), Pleurotus ostreatus (oyster), and Grifola frondosa (maitake). Monolayers were subsequently washed and incubated with medium alone or containing the pro-inflammatory cytokine $\mathrm{IL}-1 \beta(5 \mathrm{ng} / \mathrm{mL})$ for $6 \mathrm{~h}$ to upregulate pro-atherosclerotic adhesion molecules (AM). AM expression was assayed by ELISA and binding of U937 human monocytes pre-loaded with fluorescent dye was determined.

Results: White button mushrooms consistently reduced $(\mathrm{p}<0.05)$ VCAM-1, ICAM-1, and E-selectin-1 expression, whereas other test mushrooms significantly modulated AM expression singly, collectively, or combinatorially. All mushrooms, however, significantly reduced binding of monocytes to both quiescent and cytokine-stimulated monolayers.

Conclusion: These data provide evidence that dietary mushrooms can inhibit cellular processes such as adhesion molecule expression and ultimate binding of monocytes to the endothelium under pro-inflammatory conditions, which are associated with CVD. As a result, these findings support the notion that dietary mushrooms can be protective against CVD.

\footnotetext{
Correspondence: Keith.R.Martin@asu.edu
}

Healthy Lifestyles Research Center, College of Nursing and Health

Innovation, Arizona State University, 6950 East Williams Field Road, Mesa, AZ 85212, USA

\section{Biomed Central}

C 2010 Martin; licensee BioMed Central Ltd. This is an Open Access article distributed under the terms of the Creative Commons Attribution License (http://creativecommons.org/licenses/by/2.0), which permits unrestricted use, distribution, and reproduction in any medium, provided the original work is properly cited. 


\section{Background}

Cardiovascular disease (CVD) is a leading cause of morbidity and mortality in the United States as well as globally in both developed and developing countries [1]. Epidemiological studies show that regular consumption of plants, i.e., fruits and vegetables, is strongly and convincingly associated with a reduced risk of chronic disease including CVD $[2,3]$. This protection presumably occurs due to a plethora of bioactive phytochemicals that can modulate processes including the immune response, inflammation and antioxidant activity $[4,5]$. In addition to plants, dietary fungi, viz., mushrooms, also contain a diverse array of biologically active molecules rendering them potentially protective against CVD $[6,7]$. In fact, dietary mushrooms have been shown in previous studies to improve cardiovascular health, stimulate immune function, contribute to glucose homeostasis, and to modulate detoxification, as well as exert antiallergic, anti-tumor, anti-viral, antibacterial, antifungal, and anti-inflammatory activities [5,8-10]. As a result, both cellular components and secondary metabolites of myriad dietary mushrooms have been used in treatment for a variety of diseases [11]. While previous results have been compelling, research has largely focused on specialty or exotic mushrooms associated with the Far East including shiitake, maitake, and reishi. However, the white button mushroom is the most frequently consumed mushroom in the United States and could be equally effective in preventing or slowing CVD [10].

The etiology of CVD involves, in part, a complex process of development and deposition of cholesterolladened fatty streaks within aortic blood vessels and appears associated with oxidative stress and inflammation $[12,13]$. Accumulating evidence suggests also a critical link between inflammation and metabolic syndrome, CVD, and diabetes [14]. Pro-inflammatory cytokines such as IL-1 $\beta$, chemokines, and upregulation of several key adhesion molecules including intercellular adhesion molecule-1 (ICAM-1), vascular cell adhesion molecule-1 (VCAM-1), and endothelial-leukocyte adhesion molecule-1 (ELAM-1 or E-selectin) have been shown to contribute significantly to CVD by initiating an interaction between the vascular endothelium and monocytes, precursors to foam-ladened macrophages $[13,15]$. The increased expression of adhesion molecules, migration of monocytes into the aortic subendothelium, and foam cell formation can contribute to atherosclerotic plaque development and premature cardiovascular disease and death. It has been demonstrated that an atherogenic diet high in dietary fat such as the Western diet can also rapidly induce adhesion molecules and contribute to atherogenesis [16]. Some dietary agents, such as mushrooms, can inhibit or attenuate these processes, which would be beneficial in slowing or preventing downstream chronic disease.

Despite emerging evidence, little attention has been focused on the potential protective role of edible mushrooms against atherogenesis in a biological context or determination of a specific underlying mechanism. Moreover, a lingering question is whether common dietary mushrooms can be as effective as specialty, or exotic, mushrooms. In this research, we have determined whether both common mushrooms and specialty mushrooms can modulate critical events leading to atherogenesis such as pro-inflammatory, cytokineinduced upregulation of adhesion molecule expression to include VCAM-1, ICAM-1, and E-selectin. We selected as test mushrooms Agaricus bisporus (white button and crimini varieties), Lentinula edodes (shiitake), Pleurotus osteratus (oyster), and Grifola frondosa (maitake). After analyzing VCAM-1, ICAM-1, and Eselectin expression, we assessed whether significant reductions in binding of human monocytes to aortic endothelium in a quiescent or a pro-inflammatory environment occurred. We hypothesized that preincubation of human aortic endothelial cells (HAEC) with dimethylsulfoxide (DMSO) extracts of whole mushrooms would inhibit the adverse binding of U937 human monocytes to cytokine-stimulated aortic endothelium using an in vitro model of atherogenesis.

\section{Methods}

\section{Preparation and delivery of mushrooms}

Samples of mushrooms were collected from The Pennsylvania State University Mushroom Test Demonstration Facility and Mushroom Research Center and Modern Mushroom Farm, Inc. (Toughkennamon, PA) as outlined in Table 1. Mushrooms were grown using the standard tray system under controlled conditions and were harvested at the optimum maturation stage with closed caps that were 2.0-2.5 inches in diameter [17]. Mushrooms from the second break of the A. bisporus

\section{Table 1 Mushrooms selected for testing}

\begin{tabular}{|c|c|c|c|}
\hline $\begin{array}{l}\text { Test } \\
\text { Mushroom }\end{array}$ & Genus/Species & Sample type & Source \\
\hline Shiitake & $\begin{array}{l}\text { Lentinula } \\
\text { edodes }\end{array}$ & Basidioma & $\begin{array}{l}\text { Modern Mushroom } \\
\text { Farm }\end{array}$ \\
\hline Crimini & $\begin{array}{l}\text { Agaricus } \\
\text { bisporus }\end{array}$ & $\begin{array}{l}\text { brown } \\
\text { mushroom }\end{array}$ & Penn State University \\
\hline Oyster & $\begin{array}{l}\text { Pleurotus } \\
\text { ostreatus }\end{array}$ & Basidioma & $\begin{array}{l}\text { Modern Mushroom } \\
\text { Farm }\end{array}$ \\
\hline Maitake & Grifola frondosa & Basidioma & $\begin{array}{l}\text { Modern Mushroom } \\
\text { Farm }\end{array}$ \\
\hline White Button & $\begin{array}{l}\text { Agaricus } \\
\text { bisporus }\end{array}$ & all crops & Penn State University \\
\hline
\end{tabular}


crops were tested and included brown (crimini) mushrooms and the common white button mushrooms. Specialty mushrooms were harvested using standard mycology protocols and harvested on peak production days [17].

Harvested mushroom crops were randomly sampled, cleaned, sliced, and stored at $0^{\circ} \mathrm{C}$ for $24 \mathrm{~h}$. Samples were later freeze-dried (Model 15 SRC-X; Virtis Genesis Co, Inc., Gardiner, NY), ground to a fine powder, and sieved through a 16 mesh screen. Mushroom powders were collected in sterile sample bags (Fisher Scientific, Pittsburgh, PA) and stored in the dark at room temperature in desiccators prior to analysis.

After analyses, lyophilized mushroom powders were stored desiccated at $-80^{\circ} \mathrm{C}$ in the dark until use. Stock solutions of each test mushroom were prepared by dissolving $100 \mathrm{mg}$ mushroom powder into $10 \mathrm{~mL}$ DMSO (Sigma, St. Louis, MO) in tubes immersed in ice followed by three cycles of 2 min each of sonication using a Bransonic sonifier (Model S450, Danbury, CT). Immediately prior to experiments, aliquots of stock solutions $(0.01 \mathrm{~mL})$ were independently diluted into endothelial cell basal medium (EBM) medium to produce $0.1 \mathrm{mg} / \mathrm{mL}$ working concentrations each with $1 \%$ $(\mathrm{v} / \mathrm{v})$ DMSO. DMSO was not toxic at this concentration as determined by viability assays when compared to control cultures with medium alone (data not shown).

\section{Cell culture}

HAEC were purchased from Clonetics Laboratories (San Diego, CA) and cultured in EBM (Clonetics, San Diego, CA). The medium contained 10\% fetal bovine serum (FBS), hydrocortisone, vascular endothelial growth factor, insulin-like growth factor, fibroblast growth factor, gentamicin, epidermal growth factor, heparin, and ascorbic acid at concentrations provided as a kit by the manufacturer (Clonetics, San Diego, CA). HAEC were seeded in $1 \%$ gelatin (Sigma, St. Louis, MO) coated Corning T-75 flasks, 24, and 96well plates (Corning, NY). Medium was changed every other day and cells were subcultured by trypsinization, resuspension, and reseeding to flasks to propagate cultures. For experiments, HAEC were used for three passages (number of times subcultured) since they are non-transformed and non-immortalized. For this study, cells were grown to confluence and each assay was replicated 3-4 times in quadruplicate using passages 6-8. U-937 monocytes (ATCC, Rockville, MD) grew in suspension culture in RPMI-1640 medium (Sigma, St. Louis, MO) supplemented with 10\% FBS, 2 mM glutamine, $100 \mathrm{U} / \mathrm{mL}$ penicillin, and $100 \mathrm{ug} / \mathrm{mL}$ streptomycin. Medium was exchanged every $3 \mathrm{~d}$ and cells were subcultured weekly.

\section{Cytotoxicity of mushroom powders}

Monolayers of HAEC were incubated overnight with media containing DMSO vehicle alone $(1 \% \mathrm{v} / \mathrm{v})$ or containing the test mushroom powders. Cytotoxicity was determined by changes in morphology as determined by light microscopy and trypan blue exclusion as an indicator of viability.

\section{Adhesion molecule expression}

HAEC were cultured in 24-well plates until confluent and were incubated overnight with mushroom powders dissolved in cell culture medium as described above. After incubation, monolayers were washed twice with phosphate buffered saline (PBS) $(0.5 \mathrm{~mL} /$ well $)$ and further incubated with medium alone or with IL-1 $\beta$ $\left(5 \mathrm{ng} / \mathrm{mL}\right.$ ) for $6 \mathrm{~h}$ at $37^{\circ} \mathrm{C}$. Medium was removed and monolayers were fixed with $1 \%$ formaldehyde at $25^{\circ} \mathrm{C}$ for $30 \mathrm{~min}$. Monolayers were washed with $\mathrm{PBS}$ and blocked with $10 \%$ FBS in PBS for $1 \mathrm{~h}$ to reduce nonspecific binding and background. Monoclonal antibodies against human VCAM-1, ICAM-1, and E-selectin (BD Pharmingen, San Diego, CA) were added at 5, 1, and $10 \mu \mathrm{g} / \mathrm{mL}$, respectively, in PBS with $10 \%$ FBS for $1 \mathrm{~h}$ at $25^{\circ} \mathrm{C}$. The secondary antibody, horseradish-conjugated anti-mouse IgG (Santa Cruz, CA), was added at a 1:400 dilution and incubated at $25^{\circ} \mathrm{C}$ for $2 \mathrm{~h}$. Subsequently and after washing with PBS, horseradish peroxidase substrate was added and cells were incubated for $1 \mathrm{~h}$ to develop the colorimetric endpoint (Bio-Rad, Hercules, CA). The optical densities, or absorbances, were read at $405 \mathrm{~nm}$ using a Tecan SpectraFluor multi-well plate reader (Tecan, Research Triangle Park, NC).

\section{Fluorescent labeling of monocytes}

U-937 cells (ATCC, Rockville, MD), a human monocyte cell line, was used to test adherence to HAEC monolayer [18]. Prior to co-incubation, U-937 cells were fluorescently labeled by incubating cells $\left(2 \times 10^{6} \mathrm{cell} / \mathrm{mL}\right)$ with $5 \mu \mathrm{M}$ BCECF-AM/L [2', 7'-bis-(2-carboxyethyl)-5 (and 6)-carboxy-fluorescent acetoxymethyl ester] (Molecular Probes, Eugene, OR) in EBM medium for $30 \mathrm{~min}$ at $37^{\circ} \mathrm{C}$ and $5 \% \mathrm{CO}_{2}$ as described previously [19]. BCECF-AM, a non-fluorescent lipophilic compound, readily enters cells where it is modified to become fluorescent and retained by cells. BCECF-AM was prepared as a $1 \mathrm{mg} / \mathrm{mL}$ stock in DMSO and stored at $-80^{\circ} \mathrm{C}$. After labeling, cells were washed twice with PBS containing 1\% FBS to remove excess dye. U937 cells were then resuspended in medium $\left(5 \times 10^{5}\right.$ cells $\left./ \mathrm{mL}\right)$ and added $(0.5 \mathrm{~mL} /$ well $)$ to HAEC monolayers as described below.

\section{U-937 monocyte binding to HAEC}

HAEC were cultured in gel-coated 24-well plates until confluent then incubated overnight with mushroom 
powders dissolved in cell culture medium as described above. After incubation, monolayers were washed twice with PBS $(0.5 \mathrm{~mL} /$ well $)$ and further incubated with IL-1 $\beta(5 \mathrm{ng} / \mathrm{mL})$ for $6 \mathrm{~h}$ at $37^{\circ} \mathrm{C}$. U-937 cells, labeled as described above, were incubated with HAEC for $30 \mathrm{~min}$ at $37^{\circ} \mathrm{C}$ and $5 \% \mathrm{CO}_{2}$. After incubation, non-adherent cells were removed by washing twice with PBS containing $1 \%$ FBS. The attached cells were lysed with $0.5 \mathrm{~mL}$ of $50 \mathrm{mM}$ Tris buffer ( $\mathrm{pH}$ 7.6) containing 1\% sodium dodecyl sulfate (SDS). The fluorescent intensity was measured at excitation and emission wavelengths of 485 and $535 \mathrm{~nm}$, respectively, with a Tecan Spectrafluor fluoresence multiwell plate reader.

\section{Statistical analysis}

Data were analyzed using the Students $t$ test to compare individual treatment groups with the respective controls. Values are displayed as means + SEM and $\mathrm{p}<0.05$ is considered significant.

\section{Results}

\section{VCAM-1 expression}

Increased expression of adhesion molecules and binding of monocytes to HAEC are critical events in atherogenesis. As a result, we first analyzed the expression of VCAM-1 after pre-incubation with medium alone or containing mushroom powder. After stimulation with IL$1 \beta$ for 6 h, VCAM- 1 expression significantly increased by
3.8 fold in DMSO vehicle control cells (Fig. 1). There were no differences between stimulated DMSO vehicletreated cells and stimulated cells incubated with medium alone. After preincubation with mushrooms, VCAM-1 expression was marginally, but significantly, reduced by 24.8 amd $10.5 \%$ after crimini and white button mushroom powder, respectively. Basal expression of VCAM-1 was not significantly altered after pre-incubation with mushrooms.

\section{ICAM-1 expression}

We next analyzed the expression of the adhesion molecule ICAM-1. Basal ICAM-1 expression was higher than either basal VCAM-1 or E-selectin as observed previously and routinely and was not altered by pre-incubation with solutions from mushroom powder. Incubation with IL- $1 \beta$ increased significantly ICAM- 1 expression by 2 -fold as expected (Fig. 2). After pre-incubating with mushroom extracts, ICAM-1 expression was marginally, but significantly, decreased by white button mushroom powder by $8 \%$. Other test mushrooms did not significantly reduce ICAM-1 adhesion molecule expression.

\section{E-selectin expression}

We next analyzed the expression of the adhesion molecule E-selectin. Basal expression remained low and unchanged in all cultures including treatment groups (Fig. 3). After incubation with IL-1 $\beta$, E-selectin

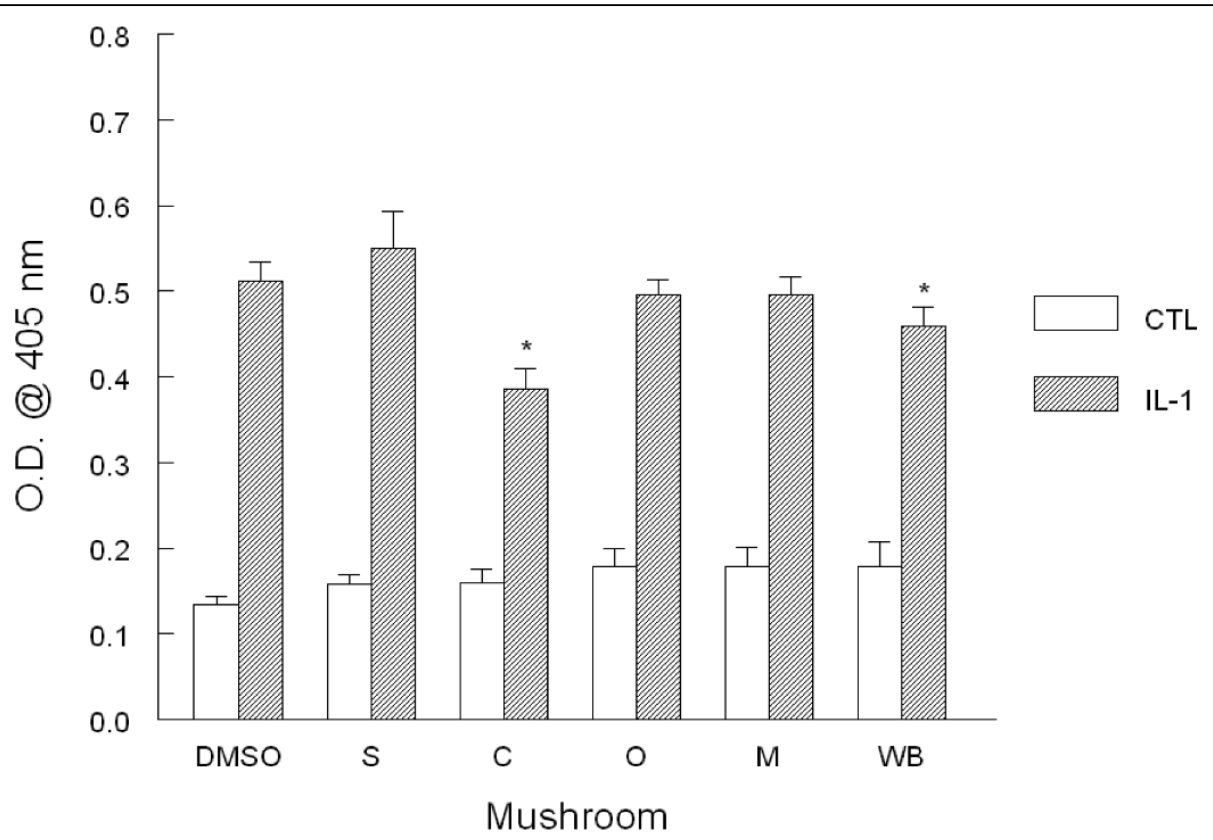

Figure 1 VCAM-1 adhesion molecule expression in HAEC. Monolayers were incubated overnight with 1\% (v/v) DMSO alone (DMSO) or with mushroom powder $(0.1 \mathrm{mg} / \mathrm{mL})$ including shiitake $(\mathrm{S})$, crimini $(C)$, oyster $(\mathrm{O})$, maitake $(\mathrm{M})$, and white button $($ WB). Cell monolayers were washed then incubated with medium alone or IL-1 $(5 \mathrm{ng} / \mathrm{mL})$ for $6 \mathrm{~h}$. After harvesting, VCAM-1 expression was determined by ELISA. Data indicate mean optical density (O.D.) \pm SEM and are representative of 3-4 experiments each performed in quadruplicate. ${ }^{*} p<0.05$ vs. control. 


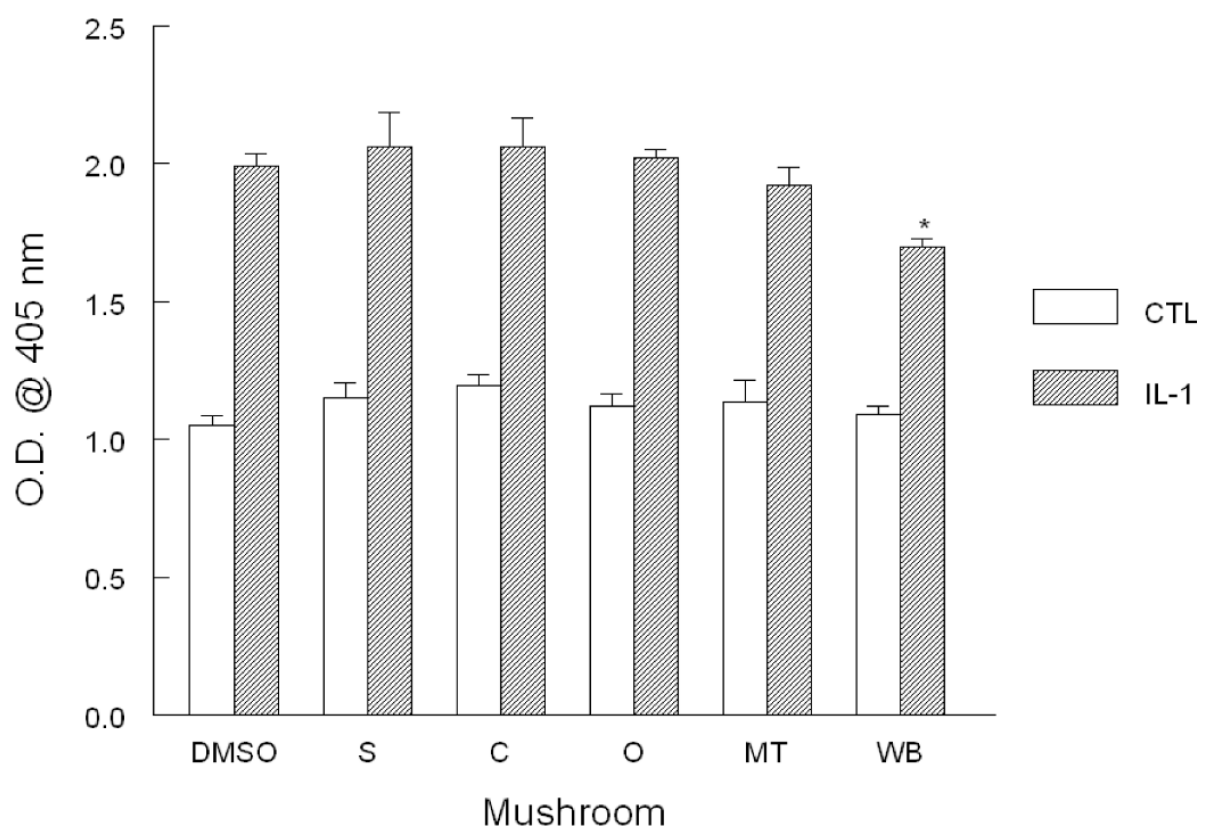

Figure 2 ICAM-1 adhesion molecule expression in HAEC. Monolayers were incubated overnight with 1\% ( $\mathrm{v} / \mathrm{v})$ DMSO alone (DMSO) or with mushroom powder $(0.1 \mathrm{mg} / \mathrm{mL})$ including shiitake $(\mathrm{S})$, crimini $(\mathrm{C})$, oyster $(\mathrm{O})$, maitake $(\mathrm{M})$, and white button (WB). Cell monolayers were then washed and incubated with medium alone or $\mathrm{IL}-1 \beta(5 \mathrm{ng} / \mathrm{mL})$ for $6 \mathrm{~h}$. After harvesting, ICAM-1 expression was determined by ELISA. Data indicate mean optical density (O.D.) \pm SEM and are respresentative of 3-4 experiments each performed in quadruplicate. ${ }^{*} p<0.05$ vs. control.

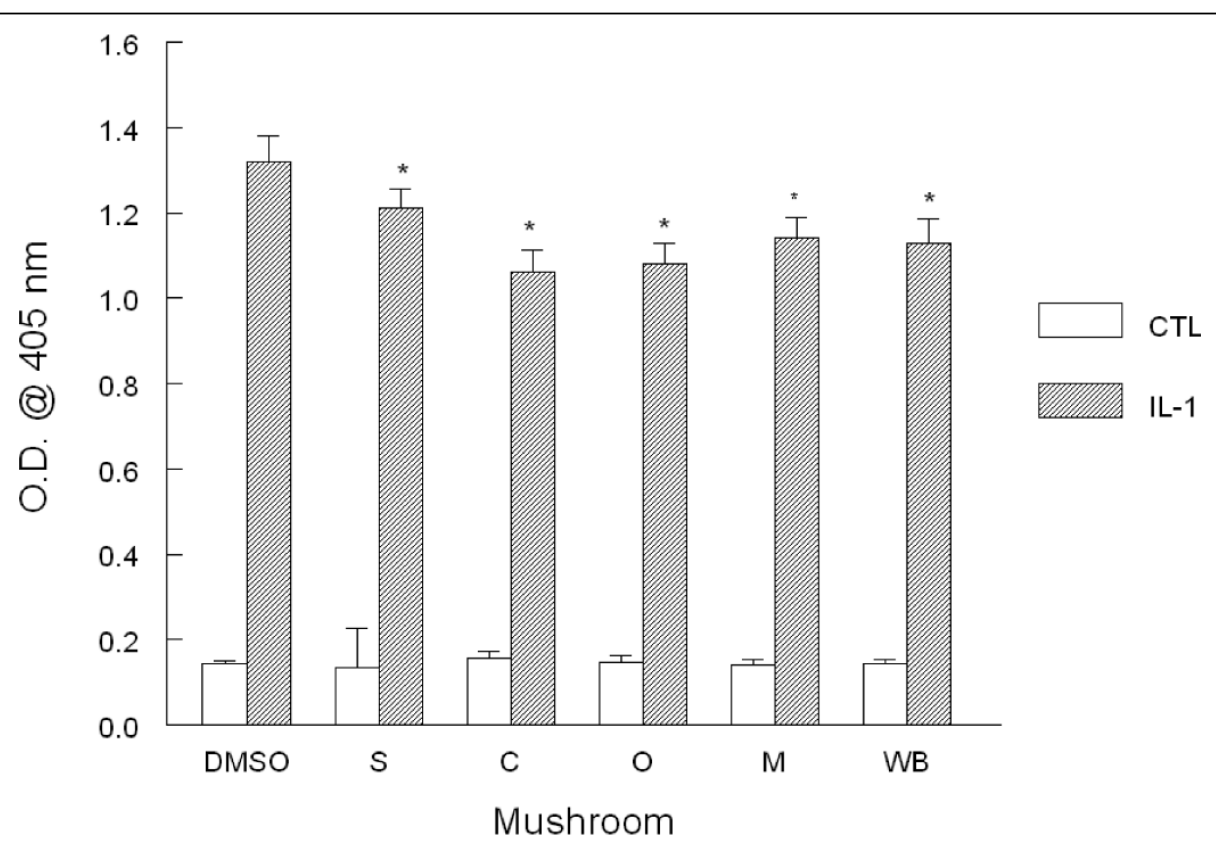

Figure 3 E-selectin adhesion molecule expression in HAEC. Monolayers were incubated overnight with 1\% ( $/ \mathrm{v}$ ) DMSO alone (DMSO) or with mushroom powder $(0.1 \mathrm{mg} / \mathrm{mL})$ including shiitake $(\mathrm{S})$, crimini $(\mathrm{C})$, oyster $(\mathrm{O})$, maitake $(\mathrm{M})$, and white button (WB). Cell monolayers were washed then incubated with medium alone or $\mathrm{IL}-1 \beta(5 \mathrm{ng} / \mathrm{mL})$ for $6 \mathrm{~h}$. After harvesting, E-selectin expression was determined by ELISA. Data indicate mean optical density (O.D.) \pm SEM and are representative of 3-4 experiments each performed in quadruplicate. ${ }^{*} p<0.05$ vs. control. 


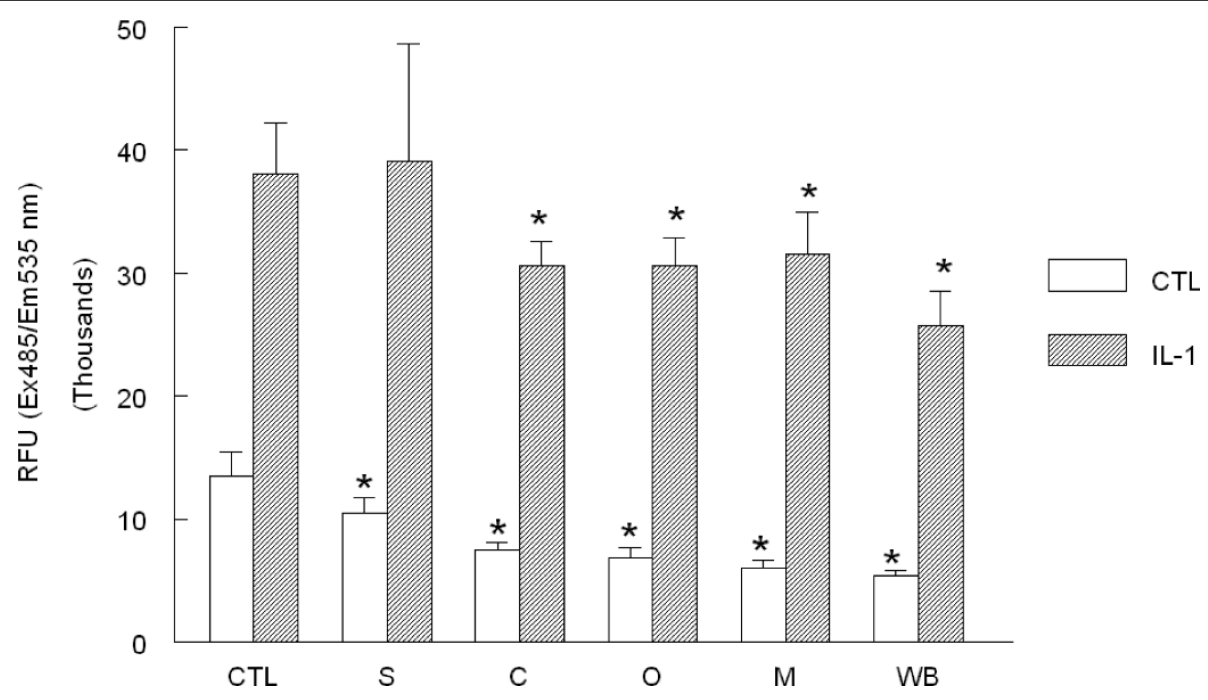

Figure 4 Binding of U937 human monocytes to HAEC. HAEC monolayers were incubated overnight with 1\% (v/v) DMSO alone (DMSO) or with mushroom powder $(0.1 \mathrm{mg} / \mathrm{mL})$ including shiitake $(\mathrm{S})$, crimini $(\mathrm{C})$, oyster $(\mathrm{O})$, maitake $(\mathrm{M})$, and white button (WB). Monolayers were washed then incubated with medium alone or containing IL-1 $(5 \mathrm{ng} / \mathrm{mL})$ for $6 \mathrm{~h}$. After washing again to remove IL-1 $\beta$, fluorescently labeled U937 cells were co-incubated with HAEC for 30 min at $37^{\circ} \mathrm{C}$. HAEC monolayers and bound U937 cells were harvested and the total fluorescence was analyzed to determine monocyte binding. Data indicate mean relative fluorescent units (RFU) \pm SEM and are resentative of 3-4 experiments each performed in triplicate. ${ }^{*} p<0.05$ vs. control.

expression significantly increased by 9.2 -fold. After preincubation with mushrooms, E-selectin expression was significantly reduced by $8,20,18,13$, and $14 \%$ after preincubation with shiitake, crimini, oyster, maitake, and white button mushroom powders, respectively.

\section{Binding of U937 monocytes}

We next analyzed the capacity for pre-loaded U937 monocytes to bind and adhere to human aortic endothelial cells. Pre-incubation with mushrooms reduced adhesion of monocytes to unstimulated HAEC significantly by $23,44,50,55$, and $60 \%$ for shiitake, crimini, oyster, maitake, and white button mushroom powders, respectively (Fig. 4). Incubation with IL-1 $\beta$ significantly increased monocyte adherence to HAEC by 2.7-fold (Fig. 4). Pre-incubation with crimini, oyster, maitake, and white button significantly reduced U937 adhesion to IL- $1 \beta$-stimulated HAEC by $18,18,16$, and $26 \%$, respectively. Pre-incubation with shiitake was not different from control cultures and did not affect binding of monocytes.

\section{Discussion}

This study is the first to demonstrate the capacity of whole mushrooms, delivered as DMSO extracts, to reduce adhesion molecule expression with subsequent reductions in human monocyte binding to human aortic endothelial cells. Specifically, we have demonstrated that dietary mushrooms significantly reduced cell surface expression of VCAM-1, ICAM-1, and E-selectin. Furthermore, there were significant reductions in adhesion of pre-loaded human monocytes to both unstimulated, or quiescent, and pro-inflammatory, cytokinestimulated HAEC as summarized in Table 2. The health implications are that diverse mushrooms, including common and specialty mushrooms can protect against cardiovascular disease by interfering with events that contribute to atherogenesis.

Table 2 Summary of effects by mushrooms on adhesion molecule expression and monocyte binding

\begin{tabular}{|c|c|c|c|c|c|c|c|}
\hline Mushroom & VCAM-1 & ICAM-1 & E-selectin & Binding-U* & $\%$ & Binding-S & $\%$ \\
\hline Shiitake & & & reduced & reduced & 23 & no change & 0 \\
\hline Crimini & reduced & & reduced & reduced & 44 & reduced & 18 \\
\hline Oyster & & & reduced & reduced & 50 & reduced & 18 \\
\hline Maitake & & & reduced & reduced & 55 & reduced & 16 \\
\hline White button & reduced & reduced & reduced & reduced & 60 & reduced & 26 \\
\hline
\end{tabular}

*U, unstimulated HAEC cells; S, stimulated with IL-1 $\beta$. 
Mushrooms have received marginal attention regarding their potential role in protecting against cardiovascular disease although studies have suggested a protective effect against CVD. For example, powders (5\% dry weight) of shiitake, maitake, and Agaricus bisporus significantly decreased plasma cholesterol levels and blood pressure in rats presumably due to the bioactive agent eritadenine [20-22]. Furthermore, dietary oyster mushrooms ( $P$. ostreatum) also elicited a hypocholesterolemic effect and inhibited lipid peroxidation, a process linked to oxidative stress, in rabbits [23,24]. This is in agreement with our results in that white button and crimini (A. bisporus), maitake and oyster significantly reduced AM expression and monocyte binding, which would counter a hypercholesterolemic, or hyperlipidemic, effect. That is, even with elevated plasma levels of lipids, the reduced expression of AM and subsequent inhibition of binding of monocytes would interrupt the atherogenic process. This is further supported by the observation that a $10 \%(\mathrm{w} / \mathrm{w})$ oyster mushroom diet significantly reduced both the incidence and size of aortic atherosclerotic plaques in rabbits suggesting interaction with physiological and molecular processes of atherogenesis $[23,24]$. Percario et al. also showed that a natural antioxidant-rich mushroom, Agaricus sylvaticus, could prevent the development of atherosclerosis in an environment of hypercholesterolemia using a rabbit model [25]. Collectively, several studies suggest that dietary mushrooms can inhibit or slow CVD although more research is needed.

In this report, we have demonstrated that both common and specialty mushrooms can modulate processes at the cellular level where AM expression is attenuated and binding of monocytes blunted. Others have identified alternative mechanisms for a potential CVD protective effect by dietary mushrooms. For example, oyster mushrooms (10\% of diet) reduced significantly the incidence of atherosclerotic plaques in rabbits as well as plaque size by $26 \%$ compared to the control group and prevented formation of atheromas, reduced foam cell number, and reduced coronary arterial injury [24]. Other dietary antioxidants (vitamins $\mathrm{C}$, E, and beta carotene) have been shown to reduce lesion area by reducing concentrations of soluble adhesion molecules by $36-61 \%$ in mice [26]. This observation is important because soluble AM have been proposed as a critical assessment tool for asymptomatic CVD in high-risk patients [27]. While we did not measure soluble AM in this study, the capacity of the test mushrooms to reduce cell surface expression in HAEC is equally compelling as a protective mechanism. Other proposed mechanisms of cardioprotection in rodents consuming Grifola frondosa, Inonotus obliquus, Antrodia xantha, and Rigidoporus ulmarius include inhibition of COX-1 and COX-2 activities, inhibition of iNOS via reduced NF-kB binding, and potent antiangiogenesis activity [28-30]. Collectively, the data support the capacity of both exotic and commonly consumed mushrooms to beneficially modulate numerous processes associated with atherogenesis.

We also noted in this study that the three most frequently measured AM including VCAM-1, ICAM-1 and E-selectin, were reduced singly, collectively, or in various combinations of two after incubation with mushrooms yet binding of monocytes was consistently reduced after incubation with each mushroom extract. Others have shown similar results with different dietary agents using the HAEC cell model, which is a non-transformed primary endothelial cell line. For example, pretreatment of HAEC with a red wine polyphenol extract significantly inhibited oxysterol-induced cell surface expression of adhesion molecules and subsequent adherence of monocytes to monolayers by inhibiting primarily VCAM-1 [31]. Subsequent studies by Naito et al. showed that tocotrienols exerted a similar effect [32]. Dietary consumption of antioxidant polyphenols from avenathramide-enriched mixtures (AEM) derived from oats significantly reduced IL- $1 \beta$-stimulated VCAM- 1 , ICAM1 , and E-selectin expression in HAEC by 50,20 , and $20 \%$ respectively, and reduced $\mathrm{U} 937$ binding at concentrations as low as $20 \mu \mathrm{g} / \mathrm{mL}$ [33]. Ginkgo biloba extracts reduced both VCAM-1 and ICAM-1 and adhesion of monocytes to HAEC [34]. In a study using structurally related dietary carotenoids, Martin et al. found that preincubation of HAEC with beta-carotene, lutein and lycopene significantly reduced VCAM-1 expression, betacarotene and lutein significantly reduced E-selectin expression, and beta-carotene, lutein and lycopene significantly reduced the expression of ICAM-1, yet lycopene was the only carotenoid to significantly reduce binding of U937 to HAEC [19]. The antioxidant pyrrolidine dithiocarbamate selectively inhibited in HUVEC cells VCAM-1 induction, but not ICAM-1, after stimulation with TNF- $\alpha$ and LPS. E-selectin was only partially inhibited after TNF- $\alpha$ incubation [35]. Pretreatment of HUVECs with vitamin $\mathrm{E}$ and probucol significantly reduced the expression of VCAM-1 induced by oxidized LDL, but did not reduce expression of ICAM-1 [36]. In contrast, the well recognized antioxidants $\mathrm{N}$-acetyl-Lcysteine and troglitazone, an antidiabetic agent, reduced or completely abolished VCAM-1, E-selectin, and ICAM-1 expression in endothelial cells after pro-oxidant signals including oxidized LDL and TNF- $\alpha$ [37]. Thus, each of the three commonly tested AM can be modulated either singly or in combination by diverse dietary agents and typically at least one, but often more, are inhibited. This suggests that attenuation of at least one AM, without specificity as to which one, may be adequate for inhibition of binding of monocytes but also 
that there are many other contributors to this process that may not be measured.

It is noteworthy that mushrooms also contain high levels of bioactive agents including polyphenols and the novel antioxidant ergothioneine, which is produced exclusively in mushrooms and some bacteria $[38,39]$. Dietary polyphenols such as catechin and quercetin have been shown to significantly reduce VCAM-1 expression and binding of monocytes to HAEC and ergothioneine exerts antioxidant activity that may be protective in a pro-inflammatory environment [40-42]. The test mushrooms used in this study have been analyzed and found to contain considerable amounts of both ergothioneine and total polyphenols $[43,44]$. Moreover, all test mushrooms exhibited significant antioxidant capacities using assays for oxygen radical absorbance capacity (ORAC), and hydroxyl (HORAC), peroxynitrite (NORAC), and superoxide (SORAC) radical averting capacity. Mushrooms also contain high levels of selenium and copper, essential micronutrients, needed for proper function of antioxidant enzymes, which can reduce oxidative stress and inflammation often found in CVD [45]. It is possible that varying levels of these bioactive agents alone or in combination contributed to the beneficial effects observed.

\section{Conclusions}

In conclusion, dietary mushrooms sampled from both common, which are routinely consumed in the United States, and specialty mushrooms interfered with processes critical to atherogenesis and cardiovascular disease. These findings further support the notion that consumption of not only fruits and vegetables, but also dietary fungi, viz., mushrooms, is an important approach to minimizing CVD risk. Moreover, common, readily available and affordable mushrooms such as white button, or Agaricus bisporus, as well as specialty mushrooms including shiitake appear particularly beneficial to health.

\section{Acknowledgements \\ This present study was supported jointly by a grant from the Mushroom Council (San Jose, CA, USA) and the Australian Mushroom Growers Association (AMGA) under grant \#MU07015 to KRM. We thank Margherita Cantorna, PhD, for providing lyophilized mushroom powders and Karla J. Martin, MS, for comments and suggestions during manuscript preparation. We thank Carol Johnston, PhD, for assistance with statistics.}

\section{Authors' contributions}

KRM conceived and designed the study, performed the experiments, analyzed samples, gathered data, conducted statistical analyses, and prepared the draft manuscript. The author has read and approved the final manuscript.

\section{Competing interests}

The author declares that they have no competing interests.
References

1. Gaziano T, Bitton A, Anand S, Abrahams-Gessel S, Murphy A: Growing epidemic of coronary heart disease in low- and middle-income countries. Curr Probl Cariol 2010, 35:72-115.

2. Willett W: Diet and health: what should we eat? Science 1994, 264:532-537.

3. Joshipura K, Hu F, Manson J, Stampfer M, Rimm E, Speizer F, Colditz G, Ascherio A, Rosner B, Spiegelman D, Willett W: The effect of fruit and vegetable intake on risk for coronary heart disease. Ann Intern Med 2001, 134:1106-1114.

4. De Caterina R, Zampolli A, Del Turco S, Madonna R, Massaro M: Nutritional mechanisms that influence cardiovascular disease. Am J Clin Nutr 2006, 83:421S-426S.

5. De Kok T, Van Breda S, Manson M: Mechanisms of combined action of different chemopreventive dietary compounds. Eur J Nutr 2008, 47:51-59.

6. Chang R: Functional properties of edible mushrooms. Nutr Rev 1996, 54:91-93.

7. Rajewska J, Balasinska B: Biologically active compounds of edible mushrooms and their beneficial impact on health. Postepy Hig Med Dosw 2004, 58:352-357.

8. Borchers A, Krishnamurthy A, Keen C, Meyers F, Gershwin M: The immunobiology of mushrooms. Exp Biol Med 2008, 233:259-276.

9. Borchers A, Keen C, Gershwin M: Mushrooms, tumors, and immunity: an update. Exp Biol Med 2004, 229:393-406.

10. Mattila P, Suopaa K, Piironen V: Functional properties of edible mushrooms. Nutrition 2000, 16:694-696.

11. Wasser S, Weis A: Therapeutic effects of substances occurring in higher Basidiomycetes mushrooms: a modern perspective. Crit Rev Immunol 1999, 19:65-96.

12. Valgimigli M, Merli E, Malagutti $P$, Soukhomovskaia $O$, Cicchitell G, Macri G, Rerrari R: Endothelial dysfunction in acute and chronic coronary syndromes: evidence for a pathogenic role of oxidative stress. Arch Biochem Biophys 2003, 420:255-261.

13. Hansson G: Inflammation, atherosclerosis, and coronary heart disease New Engl J Med 2005, 352:1685-1695.

14. Haffner S: The metabolic syndrome: inflammation, diabetes mellitus, and cardiovascular disease. Am J Cardiol 2006, 97:3A-11A.

15. Virkhaus $R$, Lucchesi $B$, Simpson $P$, Shebuski $R$ : The role of adhesion molecules in cardiovascular pharmacology. J Pharmacol Exp Ther 1995, 273:569-575.

16. Li L, Cybulsky M, Gimbrone M, Libby P: An atherogenic diet rapidly induces VCAM-1, a cytokine-regulatable mononuclear leukocyte adhesion molecule, in rabbit aortic endothelium. Arterioscler Thromb Vasc Biol 1993, 13:197-204.

17. Hartman S: Calcium and selenium enrichment during cultivation improves the postharvest quality and shelf life of mushrooms (Agaricus bisporus). MS Thesis The Pennsylvania State University, University Park, PA 1998, 98.

18. DiCorletto P: Characterization of the adhesion of the human monocyte cell line U937 to cultured endothelial cells. J Clin Invest 1985, 75:01153-01161.

19. Martin K, Wu D, Meydani M: The effect of carotenoids on expression of cell surface adhesion molecules and binding of monocytes in human aortic endothelial cells. Atherosclerosis 2000, 150:265-274.

20. Jeong S, Jeong Y, Yang B, Islam R, Koyyalamudi S, Pang G, Cho K, Song C: White button mushroom (Agaricus bisporus) lowers blood glucose and cholesterol levels in diabetic and hypercholesterolemic rats. Nutr Res 2010, 30:49-56.

21. Talpur N, Echard B, Yasmin T, Bagchi D, Preuss H: Effects of niacin-bound chromium, Maitake mushroom fraction SX and (-)-hydroxycitric acid on the metabolic syndrome in aged diabetic Zucker fatty rats. Mol Cell Biochem 2003, 253:369-377.

22. Kabir Y, Yamaguchi M, Kimura S: Effect of shiitake (Lentinus edodes) and maitake (Grifola frondosa) mushrooms on blood pressure and plasma lipids of spontaneously hypertensive rats. J Nutr Sci Vitaminol 1987, 33:341-346.

23. Bobek P, Galbavy S: The oyster mushroom (Pleurotus ostreatus) effectively prevents the development of atherosclerosis in rabbits. Ceska Slov Farm 1999, 48:226-30. 
24. Bobek P, Galbavy S: Hypocholesterolemic and antiatherogenic effect of oyster mushroom (Pleurotus ostreatus) in rabbits. Nahrung 1999, 43:339-342.

25. Percario S, Odorizzi V, Souza D, Pinhel M, Gennari J, Gennari M, Godoy M: Edible mushroom Agaricus sylvaticus can prevent the onset of atheroma plaques in hypercholesterolemic rabbits. Cell Mol Biol 2008, 54:1055-1061.

26. Murphy N, Grimsditch D, Vidgeon-Hart M, Groot P, Overend P, Benson G, Graham A: Dietary antioxidants decrease serum soluble adhesion molecule (sVCAM-1, sICAM-1) but not chemokine (JE/MCP-1, KC) concentrations, and reduce atherosclerosis in C57BL but not apoE*3 Leiden mice fed an atherogenic diet. Dis Markers 2005, 21:181-190.

27. Mulvihill N, Foley J, Crean P, Walsh M: Prediction of cardiovascular risk using soluble cell adhesion molecules. Eur Heart J 2002, 23:1569-1574.

28. Zhang Y, Mills G, Nair M: Cycoloxygenase inhibitory and antioxidant compounds from the mycelia of the edible mushroom Grifola frondosa. J Agric Food Chem 2002, 50:7581-7585.

29. Park Y, Won J, Kim Y, Choi J, Park H, Lee K: In vivo and in vitro antiinflammatory and anti-nociceptive effects of the methanol extract of Inonotus obliquus. J Ethnopharmacol 2005, 101:120-128.

30. Chen S, Lu M, Cheng J, Wang D: Antiangiogenic activities of polysaccharides isolated from medicinal fungi. FEMS Microbiol Lett 2005, 249:247-254.

31. Naito $Y$, Shimozawa $M$, Manabe $H$, Kuroda $M$, Tomatsuri $N$, Uchiyama $K$, Takagi T, Yoshida N, Yoshikawa T: Inhibitory effects of red wine extracts on endothelial-dependent adhesive interactions with monocytes induced by oxysterols. Biol Res 2004, 37:231-238.

32. Naito Y, Shimozawa M, Kuroda M, Makabe N, Manabe H, Katada K, Kokura S, Ichikawa H, Yoshida N, Noguchi N, Yoshikawa T: Tocotrienols reduce 2-hydroxycholesterol-induced monocyte-endothelial cell interaction by inhibiting the surface expression of adhesion molecules. Atherosclerosis 2005, 180:19-25.

33. Liu L, Zubik L, Collins F, Marko M, Meydani M: The antiatherogenic potential of oat phenolic compounds. Atherosclerosis 2004, 175:39-49.

34. Chen J, Chen Y, Lin F, Chen Y, Lin S: Ginkgo biloba extract inhibits tumor necrosis factor-alpha-induced reactive oxygen species generation, transcription factor activation, and cell adhesion molecule expression in human aortic endothelial cells. Arterioscler Thromb Vasc Biol 2003, 23:1559-1566.

35. Marui N, Offerman M, Swerlick R, Rosen C, Ahmad M, Alexander R, Medford R: Vascular cell adhesion molecule-1 (VCAM-1) gene transcription and expression are regulated through an antioxidantsensitive mechanism in human vascular endothelial cells. J Clin Invest 1993, 92:1866-1874.

36. Cominacini L, Garbin U, Pasini A, Davoli A, Campagnola M, Contessi G, Pastorino A, Lo Cascio V: Antioxidants inhibit the expression of intercellular adhesion molecule-1 and vascular cell adhesion molecule-1 induced by oxidized LDL on human umbilical vein endothelial cells. Free Rad Biol Med 1997, 22:0117-0127.

37. Cominacini L, Garbin U, Pasini A, Davoli A, Campagnola M, Rigoni A Tosetti L, Lo Cascio V: The expression of adhesion molecules on endothelial cells is inhibited by troglitazone through its antioxidant activity. Cell Adh Comm 1999, 7:223-231.

38. Mau J, Lin H, Chen C: Antioxidant properties of several medicinal mushrooms. J Agric Food Chem 2002, 50:6072-6077.

39. Akanmu D, Cecchini R, Aruoma O, Halliwell B: The antioxidant action of ergothioneine. Arch Biochem Biophys 1991, 288:10-16.

40. Koga T, Meydani M: Effect of plasma metabolites of (+)-catechin and quercetin on monocyte adhesion to human aortic endothelial cells. Am J Clin Nutr 2001, 73:941-948.

41. Meng C, Somers P, Hoong L, Zheng X, Ye Z, Worsencroft K, Simpson J, Hotema M, Weingarten M, MacDonald M, Hill R, Marino E, Suen $K$, Luchoomun J, Kunsch C, Landers L, Stefanopoulos D, Howard R, Sundell C, Saxena U, Wasserman M, Sikorski L: Discovery of novel phenolic antioxidants as inhibitors of vascular cell adhesion molecule- 1 expression for use in chronic inflammatory diseases. J Med Chem 2004, 47:6420-6432.

42. Aruoma O, Spencer J, Mahmood N: Protection against oxidative damage and cell death by the natural antioxidant ergothioneine. Food Chem Toxicol 1999, 37:1043-1053.
43. Dubost N, Ou B, Beelman R: Quantification of polyphenols and ergothioneine in cultivated mushrooms and correlation to total antioxidant capacity. Food Chem 2007, 105:727-735.

44. Dubost N, Beelman R, Peterson D, Royse D: Identification and quantification of ergothioneine in cultivated mushrooms using liquid chromatography-mass spectroscopy. International J Med Mushrooms 2006, 8:215-222.

45. Klevay L: Lack of a recommended dietary allowance for copper may be hazardous to your health. J Am Coll Nutr 1998, 17:322-326.

doi:10.1186/1475-2891-9-29

Cite this article as: Martin: Both common and specialty mushrooms inhibit adhesion molecule expression and in vitro binding of monocytes to human aortic endothelial cells in a pro-inflammatory environment. Nutrition Journal 2010 9:29.

\section{Submit your next manuscript to BioMed Central and take full advantage of:}

- Convenient online submission

- Thorough peer review

- No space constraints or color figure charges

- Immediate publication on acceptance

- Inclusion in PubMed, CAS, Scopus and Google Scholar

- Research which is freely available for redistribution

Submit your manuscript at www.biomedcentral.com/submit
Ciomed Central 